\title{
Management science in the era of smart consumer products: challenges and research perspectives
}

\author{
Herbert Dawid $^{1}$ - Reinhold Decker ${ }^{2}$. Thomas Hermann ${ }^{3}$. \\ Hermann Jahnke ${ }^{4}$. Wilhelm Klat ${ }^{5}$ - Rolf König ${ }^{6}$. \\ Christian Stummer ${ }^{7}$
}

(C) The Author(s) 2016. This article is published with open access at Springerlink.com

\begin{abstract}
Smart products not only provide novel functionalities, but also may establish new business models, markets, or distribution channels, strengthen relationships with consumers, and/or add smart remote services. While many technical obstacles of such products have already been overcome, the broad market dissemination of smart products still poses some vital managerial challenges for decision makers. In this paper, we outline the technical potential and future trends of smart consumer products, discuss economic challenges in four scopes, namely, preference-based new product development, market analysis, supply chain design, and industry development, and, in particular, we highlight research perspectives for management science in this promising field.
\end{abstract}

Keywords Smart products $\cdot$ Management science $\cdot$ Economic challenges $\cdot$ Research perspectives

Christian Stummer

christian.stummer@uni-bielefeld.de

1 Chair of Economic Theory and Computational Economics, Bielefeld University, Universitaetsstr. 25, 33615 Bielefeld, Germany

2 Chair of Marketing, Bielefeld University, Universitaetsstr. 25, 33615 Bielefeld, Germany

3 Ambient Intelligence Group, Cluster of Excellence - Cognitive Interaction Technology (CITEC), Bielefeld University, Inspiration 1, 33619 Bielefeld, Germany

4 Chair of Management Accounting and Operations Management, Bielefeld University, Universitaetsstr. 25, 33615 Bielefeld, Germany

5 Institute for Technological Innovation, Market Development, and Entrepreneurship (iTIME), Bielefeld University, Universitaetsstr. 25, 33615 Bielefeld, Germany

6 Chair of Business Taxation, Bielefeld University, Universitaetsstr. 25, 33615 Bielefeld, Germany

7 Chair of Innovation and Technology Management, Bielefeld University, Universitaetsstr. 25, 33615 Bielefeld, Germany 


\section{Introduction}

Smart homes, smart cars, or smart cities have been part of popular visions of the future for several decades. None of them have been fully realized yet, but substantial (technological) progress has been achieved and prototypes of smart homes as well as smart cars have already been implemented. Moreover, we have witnessed successful market entries of smart products such as Nest's thermostats, Oral-B's Bluetooth toothbrush, Big Ass ceiling fans with SenseME technology, or Philips' Hue lighting. They show how traditional and well-established consumer products can be transformed into smart products by integrating intelligence-generating technologies that equip them with abilities of environment sensing, data processing, information sharing, reasoning, and/or actuation. While the industry for products which assist and/or act autonomously is still in its infancy, it has already become rather obvious that smart products have the potential to revolutionize their respective markets and it is widely expected that their era is set to start in the near future. A recent discussion on how smart products are transforming competition is provided by Porter and Heppelmann (2014). Gartner correspondingly expects a market that will be worth $\$ 69.5$ billion in 2015 and $\$ 263$ billion by 2020 (Rivera and van der Meulen 2014).

In the following, smart products are defined as consumer products that are equipped with intelligence-generating technologies including (i) sensors and/or actuation, either to gather data from the environment or to use the data to change the environment, (ii) computing power for data analysis, and (iii) optional interfaces to exchange information with their environment. It is noteworthy that smart products are often referred to as "intelligent products", i.e., both terms are used interchangeably (e.g., Meyer et al. 2009).

While companies, in most cases, loose direct access to traditional products after their adoption by the customers, the data captured and shared by smart products during product usage stretches the opportunities for companies far beyond the point of sale (Mayer 2010; Körling 2012). Smart products have capabilities for monitoring, controlling, and/or optimization and, ultimately, may even work with complete autonomy based on the vast quantities of data now available (Porter and Heppelmann 2015). Thus, smart products provide opportunities such as creating innovative products (Rijsdijk et al. 2007), applying new communication and business models (Maass and Varshney 2008), strengthening relationships with consumers (Mayer et al. 2011), reducing the information asymmetry between consumers and manufacturers (Bohn et al. 2004), establishing new markets (Rijsdijk and Hultink 2013), or adding smart remote services to a smart product (Allmendinger and Lombreglia 2005; Yang et al. 2009).

While many technical obstacles have been overcome, the upcoming market dissemination of smart products poses new managerial challenges that may be addressed by researchers from economics, business administration, and other non-technical fields (e.g., Maass and Varshney 2008; Zinkhan 2003). One such challenge stems from the high degree of innovativeness of such products which may make the added value unclear to consumers and, thus, limits the applicability of traditional approaches for eliciting consumer preferences for smart products or for estimating the willingness to pay. Furthermore, smart products may fundamentally change the way products and services are brought to the market and, thus, they may impact the "rules of engage- 
ment" in existing markets or even create new markets and/or allow for novel business models. From a supply perspective, smart products challenge firms to apply more flexible supply chain strategies and to enter interdisciplinary research and development (R\&D) collaboration with firms from as yet unrelated industries. Finally, the coming era of smart products impacts industrial structures and decision making on a large scale. Economic problems such as missing standards and underinvestment in the early stages of the industry life-cycle require public policy makers and industry leaders to develop solutions with regard to common standards and interfaces, legislation, and taxation.

The paper at hand elaborates on these and related issues, provides an overview on management science approaches that have already been successfully applied in similar contexts and, in particular, discusses research questions that need to be tackled in order to support managerial decision makers. From a researcher's perspective, it thus offers insights in the field and highlights promising research opportunities. From a practitioner's perspective, this paper may stimulate the development of proper means for management that will prove beneficial on the (bumpy) road to the era of smart products.

The advances of computing power, intelligent control, and connectivity, do not only lead to the development of smart products, but also allow for radical changes in the way production processes are designed and supply chains are organized. Industry 4.0 and decentralized production through 3D printing are key developments in this respect. Although the technological drivers of these developments are clearly related to those that make the introduction of smart products feasible, we see a conceptual distinction between processes triggered by products becoming smart and the introduction of advanced technology in the production process per se. Hence, in this paper we focus entirely on challenges associated with the introduction of smart consumer products into markets. Discussing developments in the organization of production processes and supply chains that are not directly associated with smart products therefore is beyond the scope of this paper.

In the remainder of the paper, Sect. 2 outlines the technical potential and future trends of smart products. Then, methodological challenges are discussed with respect to preference-based new product development (Sect. 3), market analysis (Sect. 4), supply chain design (Sect. 5), and industry development (Sect. 6). The paper concludes with a summary in Sect. 7.

\section{Technical potential and future trends}

The evolution of information technology follows an exponential trend of miniaturization and increase in processing speed and storage, as first predicted in Moore's law (Moore 1965) for the density of transistors on silicon chips. In turn, the trend toward smart products that do not even appear to be computers could be foreseen for decades. Since the introduction of the vision of ubiquitous computing by Weiser (1991), we have indeed witnessed an unbroken evolution toward electronics pervading our environments, from smarter household appliances (e.g., LG's Smart ThinQ refrigerator), through smartphones and smart wearables (e.g., Apple's Smart Watch), 
to everyday objects such as electric toothbrushes (e.g., Oral-B's Bluetooth toothbrush) or even to objects that, so far, have completely lacked any electronic support such as running shoes (e.g., Nike's Nike+ Training) or tennis rackets (e.g., Babolat's Play). As a result, the number of smart products per user is steadily increasing beyond what can explicitly be managed reasonably by the user, giving rise to (i) research into concepts of how ensembles of compute nodes can automatically orchestrate their behavior so that they support users even without them being aware of it, and (ii) new solutions for how users can interact with/control individual nodes in a smart environment. Ambient intelligence-electronic environments that are sensitive and responsive to the presence of people-is a growing research area that combines context-aware computing, human computer interaction (HCI), computer vision, adaptive systems, and machine learning, to name a few. As a consequence, the smartness of a product is a rather imprecise concept that depends on the average level of complexity in comparable objects/products/systems that already exist. For instance, at the time of writing (2015), a "smart" washing machine would sense the load and current time to adapt the appropriate amount of detergent and the best time to wash (when energy price is lowest) which is compatible with the users' needs.

From a technical perspective, smart products can be characterized and improved along the dimensions (i) input: sensors that allow artifacts to perceive the user or situation, including the acquisition of relevant data for their operation, (ii) output: displays, including visual, auditory or haptic signals to convey information to users, also including any actuation that changes the environment, (iii) human-computer interfaces: methods that allow users to interact with/control the artifacts, (iv) interoperability: means by which artifacts can exchange information with other artifacts, (v) integration: how artifacts can become meaningful/useful constituents of a larger-scale system, allowing the overall smart environment to become more than the sum of its parts, and last but not least (vi) resource-efficiency: how artifacts obtain/generate and save energy to deliver their service.

In past years, game-changing innovations have occurred along each of these dimensions: for instance, the introduction of low-cost 3D depth cameras such as the Microsoft Kinect now enables systems to interpret body gestures or hand postures of human users with the LEAP Motion Controller; mini laser projectors and innovations in LED/OLED can turn arbitrary surfaces into graphical user interfaces and potentially change the way we deal with illumination in buildings; sonification, the auditory display of information, allows systems to convey information without requiring users to visually focus on a specific location, offering smart attention guidance for sportsmen, dancers, or rehabilitation and physiotherapy (see Hermann et al. 2011). The broad adoption of smartphones with Android/iOS enables manufacturers of smart objects to literally cover the whole market by implementing applications (apps) for just a few platforms. Multi-touch interactive surfaces provide a highly natural and seamless way to interact with systems. Overarching integration platforms such as OpenHAB or Qivicon promise better interoperability of systems. Finally, the establishing of cloud services from global companies supports an easier integration.

There are a number of innovations which may largely influence how we interact with our environments and with others in future: Google glass, Microsoft HoloLens, and similar systems that project information right in front of the users' eye(s) may provide 
personal and permanently-available displays and interaction modes to access/control the smart environment - perhaps in future to a degree that we will not put any physical decorations in our living rooms as virtual decorations can be projected at any location (directly on the retina) the moment we look. This sort of pseudo-holographic 3D projection is not yet available, yet it could, if feasible, result in larger changes in our relationship to technology than we can foresee now. In a similar vein, the advent of highly immersive low-cost virtual reality systems such as the Oculus Rift will offer new ways for people to meet, e.g., by virtually attending meetings/conferences without traveling, but with a comparable sense of co-presence with others. In any case, the increasingly smarter physical environments and virtual/digital environments will continually blend into each other and soften the hard borders between digital and physical presence. Tangible User Interfaces (Ishii et al. 1997; Shaer and Hornecker 2010) offer many examples for similar transitions.

Currently, most smart products are isolated solutions, i.e., stand-alone products that do not require (nor are dependent on) an embedding framework. Most offer at least a Bluetooth or WiFi-Interface to connect to smartphones or the Internet. The fragmentation that can occur when a larger number of products co-exist in an environment without really cooperating indicates missed opportunities for exploiting synergies. For instance, if a smart frying pan could control the cooktop setting, energy could be saved and problems with burned meals be avoided. This, however, demands a common language for smart products to interact in, something which currently lacks established standards; nor have current smart products any awareness of what other smart products might be available in their vicinity.

A highly underestimated problem in current smart products is the challenging task of properly estimating the situation in which they are being used. In particular all user-directed sensing that relies on raw/complex signals such as natural speech, gestures, videos of the user, and/or tactile interaction patterns, require a complex and yet often still unsolved pattern recognition (at least to the degree of reliability required for practical purposes). Failures and misinterpretations of signals either force users to adapt their behavior to the system, or they become frustrated and give up. Our human expectation of being able to communicate with smart environments, particularly with virtual agents or robots, as seamlessly and naturally as we do with a human interlocutor (e.g., a butler), cannot yet be satisfied. Current technical solutions rely largely on crowdsourcing, i.e., solving the problem by collecting big data repositories from all users. For instance, Siri, the iOS speech assistant broadcasts all inquiries to Apple, allowing servers to use specialized computing capacity to interpret the signal, and at the same time to continually improve their speech models from millions of collected speech utterances. The question remains whether users have the trust in the companies that these will use their (probably sometimes quite personal) data only for these purposes.

Smart products, and particularly those in the smart home or car, offer support in diverse application areas, namely security, control, automation, awareness of relevant information, entertainment, and communication. For instance, the future smart home will save energy by automatically closing blinders at dawn, will close windows when there is rain or a storm, report intrusions, adapt the light and sound (music or ambience) to meet the needs of a situation, offer natural speech interfaces to control the 
house's various functionalities (as for instance envisioned with Amazon echo), flexibly turn a room into a game environment (as currently exemplified by Microsoft's RoomAlive), and enable seamless communication with others without the need to handle a phone. High-end cars have already become smart environments with all sorts of sensing, assistance, actuation, and entertainment. Since security plays a major role in the automotive context, this is probably where smart products can mature and find customers that later wish for similar services in their smart homes. Furthermore, car buyers may be willing to pay extra for the luxury, rendering it a suitable entry point for new technologies.

The largest challenge for smart products is, however, to bridge the interface gap between, on the one hand, the technology that becomes ever more invisible and, on the other hand, the user who is less and less aware of what smart appliances they might be using, what information these appliances collect (and share with whom), how they can be controlled, configured, taught, and used. Eventually, it is plausible that cognitive humanoid robots will evolve as flexible assistants in our houses and cities, instead of distributing the smartness into installed components, for a number of reasons: firstly, we find it natural to communicate with an interlocutor, making it easier for users to control the devices; secondly, this would allow a single (robotic) smart product to support the user everywhere, thus not requiring installations in all rooms; and thirdly: we naturally understand how and what an interlocutor can see and perceive, making it easier to deal with questions of privacy and feeling observed in our homes. Finally, a robot could (in future) perform all manipulations in home environments as we can do ourselves and thus surpass what would be possible with just home automation components or smart appliances. As our environments have evolved to be manipulated and operated by human hands and moved around in on legs, a similar (humanoid) shape is very likely to be what is most versatile and effective. However, as a robot would also be able to natively access the information part of smart environments (via the Internet), it would also serve as a gateway to control and report the status of smart home products. For this vision to become reality, large steps still need to be taken in terms of cognitive interaction technology, the research field that investigates how technical systems can deeply understand what they perceive, how to robustly manipulate physical objects and how to communicate with human users to provide assistance. First steps toward the hybrid combination of anthropomorphic robots and smart environments are being taken, for instance, in the 'Cognitive Service Robotics Apartment as Ambient Host' project at the Cluster of Excellence Cognitive Interaction Technology (CITEC) at Bielefeld University or in the Personal Robots Group at the MIT Media Lab.

It is difficult to foresee exactly how smart products will evolve and shape our daily routines, but it is certain that they will become more powerful. At least in the short run, many of them will access the user's smartphone as a gateway to offering explicit details and configuration. Different manufacturers will propagate their proprietary interfaces as long as they regard it likely to lead the market. At some time, either a single standard will be adopted, or a meta-standard will be established which will allow a set of established standards to interoperate. Until such seamless plug and play solutions (though in fact without a plug, as many devices will be wireless) is at hand, we will observe lively competition in this area. With time, they will probably become 
so cheap and commonplace that they will be as ubiquitous as electric power in a house, or a radio in a car.

Accordingly, smart products will alter industry structure and, thus, will expose companies to new competitive opportunities and threats (Porter and Heppelmann 2014). In the following, we outline techniques from management science deemed to be suitable for addressing such challenges.

\section{Preference-based new product development}

The successful design and commercialization of smart products requires the carrying out of a comprehensive planning and decision process that consists of three main phases, namely (a) new product idea generation and screening, (b) product concept development and testing and (c) technical implementation and introduction (cf. Luchs et al. 2016). In all three phases both qualitative and quantitative approaches can be used to support management decisions. In the first phase, the new product development process is characterized by high degrees of freedom allowing for fundamental changes in product design and it is dominated by rather qualitative approaches such as creativity techniques, SWOT analyses and scoring methods. Most of these approaches are matured nowadays and therefore already belong to the standard toolbox of marketing and innovation management (see, e.g., Gaubinger et al. 2015 for a recent review). A similar situation, at least from a quantitative perspective, exists regarding product concept testing in phase (b). Here, research of five decades has provided a bunch of quantitative models and methods that can be used to analyze laboratory-based new product data, among others, in order to safeguard against the risk of costly failures. Sales forecasting models, so-called simulated test market (STM) models, are considered "the most useful-and certainly most validated - tools in all of marketing research" (Clancy et al. 1994). A review worth reading in this respect can be found in Clancy et al. (2006). Current research primarily focuses on the optimization of existing STM models for fast moving consumer goods markets (Kaltenbacher and Decker 2014), which are not in the focus of this paper, whereas adaptations to durable goods have been discussed, e.g., in Urban et al. (1993). The technical implementation and introduction in phase (c), among others, focuses on the activation of economies-ofscale in manufacturing and the optimization of new product-related logistics. Another issue is modularity since the application of modular techniques allows for leveraging investments (Krishnan and Gupta 2001). Costs also dominate the question of using prototypes, possibly implemented as a collaborative approach as discussed by Bogers and Horst (2014). As organizational and/or procedural topics like these are more or less the same for smart and for non-smart products we refrain from putting a stronger focus on them. Finally, with respect to challenges that correspond with product concept development in phase (b), Luchs et al. (2016) point out that "significant prior research has addressed the difficulties of predicting a product's market acceptance." Accordingly, there has been "an emphasis on identifying the optimal product configuration from a set of possible product attributes and attribute levels, which is used as input for product design." Over and above that, the authors conclude by providing ideas that may inspire new research projects in the field of interest. For example, 
regarding the highly dynamic field of social media, they explicitly recommend the use of "user-provided information, such as product reviews, to improve existing products and to inspire new products". Following this point of view, we will put special emphasis on attribute-based smart product development using both survey and review data.

In contrast to traditional consumer durables like books, hair-dryers, or coffee machines, the novelty of smart products is often accompanied by a high level of technical complexity (see Sect. 2), which, at best, mostly implies an only blurry idea of the possibly resulting utility. Ahram et al. (2011) even point out that a key strength of user-centered smart product design is a "clear understanding of user and task requirements". By focusing on both functional and emotional antecedents Park and Lee (2014) examine and emphasize the relationship between consumers' value perception and use-diffusion. Furthermore, Rijsdijk and Hultink (2009) found that the effects of product smartness on the perceived advantageousness, compatibility, and complexity vary across product smartness dimensions as well as across product categories. They highlight a lack of research regarding the question of how other characteristics such as the form, the brand, or the price of a smart product influence its overall perception. Building up on this study, Lee (2014) shows that product smartness affects customer satisfaction. In the light of the nearly omnipresent discussion of the Internet of Things, Chang et al. (2014) studied the influence of different product characteristics on consumer purchase intention and they found that connectivity, interactivity, and intelligence positively influence purchase intention via functional experience. Finally, Ma et al. (2014) emphasize the usefulness of exploring how human behavior can change the design of smart products and services and how interactions between consumers and their self-generated data can be analyzed and fed back to the consumers in order to initiate more informed and self-aware consumption decisions. However, despite these first contributions to the understanding of how the smartness of products may influence consumer and purchasing behavior the implications for market-oriented smart product development still constitute a widely unexplored field.

Evaluating the perception of smart products on behalf of the consumers becomes particularly difficult when the focus is on such smart products that might achieve market maturity in the future and/or if significant interdependencies in a technical and economical respect exist. Considering the specificity of smart products in general and the corresponding consumer markets in particular brings up a number of research questions, the answering of which will keep management science busy in the near future:

1. What exactly does the decision process preceding the purchase of (new) smart products look like?

2. Which typical decision-making patterns can be identified and what can be said about the stability or dynamics of these patterns?

3. Which attributes of smart products are of particular importance regarding their basic acceptance on the part of potential buyers and which attributes may hamper the willingness to purchase and use them?

4. Which attributes of smart products determine the willingness to pay most and what are the main drivers of word-of-mouth? 
There are at least two basic options for approaching the above-mentioned as well as corresponding questions from a quantitative point of view, namely survey-based preference analysis and web-based consumer opinion analysis. In the first case consumer surveys, nowadays mostly based on online questionnaires, are used to elicit the preferences consumers have with respect to smart products as a whole and with respect to individual features/attributes considered important by the product management. The possibility of (i) tailoring the survey exactly to the points the researcher or product development team is interested in and of (ii) directing the measurement process to possible future features and functionalities of the smart products are clear advantages of this approach. In the following, a method based on the popular analytic hierarchy process (AHP) and recently suggested for preference measurement focusing on complex products will be adapted to the task at hand.

In contrast to survey-based or direct measurement, the rapidly increasing number of consumer reviews made available for free on the Internet provides alternative access to the information of interest. Online consumer reviews are composed of positive, negative, and/or neutral statements or evaluations made about products or services. Today, such reviews exist for almost any kind of consumer durables, including personal computers, consumer electronics, and automobiles. Even though smart products, at least to date, are still far away from being omnipresent on online review platforms, an increasing amount of reviews on products that develop in this direction (e.g., Apple's iPhone, Oral-B's Bluetooth toothbrush, or Nest's Protect) show that it should only be a matter of time before there is a higher presence. Analyzing these reviews may help to better understand what drives and what hinders the purchase of (new) smart products. Furthermore, it will help to better understand what determines positive or negative word-of-mouth which, in turn, directly influences the diffusion process (Huang et al. 2012).

There is a broad literature on multiple-criteria decision making methods that can be applied at the interface of new product development and purchase decision making. Among others, the analytic hierarchy process (AHP), the analytic network process, case-based reasoning, and data envelopment analysis have gained increasing popularity (Ayă̆ 2016; Kalluri and Kodali 2014). Furthermore, there is a large amount of papers that focus on forecasting market reactions to alternative product designs by means of conjoint analysis (see, e.g., Agarwal et al. 2015 for a recent overview in this respect).

AHP-based methods are often used to analyze complex decision processes. Handfield et al. (2002) consider the AHP to make "complex decision processes more rational by synthesizing all available information about the decision in a [...] systematic manner." The purchase of smart products - in many cases - may initiate a comprehensive cognitive process. According to Scholz et al. (2010) a decision object (e.g., a smart product) can be described by a set $A=\left\{a_{1}, \ldots, a_{h}, \ldots, a_{H}\right\}$ of attributes, where each attribute $a_{h}$ (e.g., the price or the degree of smartness) has a finite set of realizations $A_{h}=\left\{a_{h 1}, \ldots, a_{h l_{h}}, \ldots, a_{h L_{h}}\right\}$ (e.g., "low", "medium", "high"), called attribute levels. A smart product $m$ can then be represented by a vector $\boldsymbol{x}_{m}=\left(x_{m 1}, \ldots, x_{m H}\right)$, with $x_{m h} \in A_{h} \forall h, m$. Following the AHP approach the overall preference for a particular (new) smart product can be determined by dividing its overall evaluation into a finite number of sub-problems, each comprising a certain number of paired comparisons of 
attributes or attribute levels. A simple 3-layer hierarchy representing the smart product as a whole at layer 0 , its attributes at layer 1 and the corresponding attribute levels at layer 2 appears appropriate. The unknown preference weights or desirability scores of the smart product attributes or attribute levels can be computed by means of an eigenvalue approach according to Saaty (2003). Similar to conjoint analysis, these preference weights can be used to compute the relative importance of the considered smart product attributes and the part-worth utilities of the corresponding attribute levels. Both together provide a notion of how the different features of an existing smart product or a hypothetical new one are or would be perceived in the target market. Further developments of the AHP idea in the context of preference measurement for complex consumer products are the so-called pairwise comparison-based preference measurement approach (Scholz et al. 2010) and its adaptive counterpart (Meißner et al. 2010).

Preference-oriented analysis of online consumer reviews, like those made available to a broad community via Amazon.com or Epinions.com, makes use of data that already exist. An online consumer review typically contains an overall star rating, about half a dozen product attribute scores, a yes/no-recommendation, several semi-structured pros and cons, and a (mostly) unstructured free text. The pros (i.e., the perceived advantages) and the cons (i.e., perceived disadvantages) of a smart product are of particular interest since they usually represent the essentials of thesometimes - rather lengthy free texts. At the same time several studies (e.g., Decker and Trusov 2010; Lee and Bradlow 2011) emphasize the meaningfulness of the pros and cons regarding consumer-driven product evaluations. By linking the posted pros and cons to the overall star ratings the researcher can investigate how certain attributes of a smart product (e.g., a smartphone) mentioned in the pros and cons determine its overall evaluation. Similarly to the survey-based approach above, this information can then be used to develop new, or improve existing, smart products in a preference-based way. A feasible approach to building the link concerned is sketched in the following.

The ordinal scale of star ratings suggests the use of ordered probit or logistic regression with binary independent variables representing the occurrences of certain smart product attributes in the pros and cons of an online review. Recent studies on star ratings using ordered logit or ordered probit have been published by Godes and Silva (2012) and Moe and Schweidel (2012). With dependent variables $y_{l}$ denoting the ordinal-scaled star rating observed with online review $l$, and $\boldsymbol{x}_{l}^{\text {pro }}\left(\boldsymbol{x}_{l}^{\text {con }}\right)$ denoting the binary vector that represents the corresponding occurrences of the smart product attributes of interest in the pros (cons) list of review $l$, the linear relationship $y_{l}=\boldsymbol{\alpha} \boldsymbol{x}_{l}^{\text {pro }}+\boldsymbol{\beta} \boldsymbol{x}_{l}^{\text {con }}+\varepsilon \forall l$ can be formulated. The vectors $\boldsymbol{\alpha}$ and $\boldsymbol{\beta}$ of unknown regression coefficients have to be estimated from the online review data. Assuming $\varepsilon$ to be normally distributed leads to ordered probit, whereas a logistic distribution would result in ordered logit. A feasible data pre-processing and attribute extraction procedure for generating vectors $\boldsymbol{x}_{l}^{\text {pro }}$ and $\boldsymbol{x}_{l}^{\text {con }}$ from online review-based pros and cons has been suggested by Decker and Trusov (2010). The signs and absolute values of the individual coefficients, among others, indicate which attributes support the attractiveness and acceptance of a particular smart product attribute and which ones have to be considered with care because of their possibly negative impact on the overall evaluation of the smart product. 
Both approaches have in common that they can be used to simulate and predict the effects individual attributes have on the overall attractiveness of the smart product concerned, albeit from different perspectives. They are even complementary in a certain sense: A clear advantage of the survey-based approach is the fact that not just existing smart product attributes or attribute levels can be considered. Particularly in the highly innovation-driven field of smart products the inclusion of potential new attributes or attribute levels is of similar or even more importance. On the other hand, the "voice of the consumer as represented in online product reviews can serve as a filter, highlighting meaningful product attributes" (Lee and Bradlow 2011). Knowing better what really matters from the consumers' point of views may help to direct the creativity of engineers toward effectively marketable smart products. Thus, the successive use of both approaches seems to be particularly promising: First, the researcher should extract the essential aspects of available product evaluations using online review data and then he/she should complete the picture by combining the "meaningful product attributes" (Kim et al. 2013) with those attributes that, for example, convert a positively perceived "traditional" product (e.g., a standard smoke detector) into a successful smart product (e.g., smart smoke detectors like those by Birdi or Nest), if needed.

Finally, we agree with Luchs et al. (2016) that in the last decade "technical developments such as 3D printing, computer simulation, augmented reality, and online mass customization toolkits have increased the possibilities of assessing consumer response to experiential product attributes in concept optimization". Smart products increasingly stretch business models and the product development process beyond the point of sale (Mayer 2010; Körling 2012). With the opportunity to change product functionalities on the software layer even after roll-out, companies can include actual usage data collected from innovators and early adopters in the final phase of the product development process and the product life cycle. However, an in-depth discussion of this aspect would go beyond the scope of this paper. The same applies to financial dimensions of new product development such as crowdfunding via online platforms like Kickstarter (cf., e.g. Mollick 2014) and new product pricing. The price, by the way, can either be considered as an essential part of STM models or as a regular attribute in preference measurement settings. Last but not least, the sensor-based round-the-clock collection of data by smart products such as the above-mentioned smoke detectors enables data-driven improvements of follow-up product relaunches on the basis of existing usage or behavior patterns. Since this typically involves the analysis of huge amounts of data the well-developed field of data mining and the emerging big data analysis techniques (Wu et al. 2014) move into the center of interest. According to Yin and Kaynak (2015, p. 144) big data collected by smart devices "can help the manufacturer to pinpoint the preferences of the consumers and, thus, shape future products."

\section{Market analysis}

Innovation managers who are responsible for the successful market introduction of a firm's smart products and/or corresponding services typically have to cope with limited experiences with comparable products or services. The reason why is that smart prod- 
ucts may substantially change the expectations of consumers existing markets (e.g., in the market for game consoles with the introduction of 3D depth cameras as mentioned above). Smart products may also create new markets (e.g., the market for cognitive humanoid robots as assistants in our homes or cities) and/or they may establish a platform for apps which adds to the newly arising market for services. Still, managers have to make decisions with far-reaching economic consequences concerning rollout strategies, marketing activities, and/or positioning the firm in the new "ecosystem", while also taking into account (counter-) measures of competitors. It is therefore worth noting that equipping a product with intelligence-generating technologies can have more fundamental implications than "just" adding another feature or improving the performance of a product.

The washing machine mentioned above may once again serve as an example. Apparently, a smart version may receive data on energy prices through the Internet or directly from the smart grid it is connected to and uses this information for scheduling washing routines in order to save energy costs. Furthermore, the smartness of the washing machine may pave the way for business model innovations. For instance, the machine may be offered in a pay-per-use business model, using its smartness and the Internet connectivity for billing purposes, which may open the door to new market segments, e.g., with consumers who currently are not willing to purchase a premium washing machine but would consider renting one. Also, the smart washing machine could automatically order supplies of washing detergents from a web shop. This not only would be convenient for the customer, but would also open up an additional distribution channel for suppliers of washing detergents cooperating with the producer of the smart washing machine. Hence smart consumer products, by adding new product related service offerings to traditional products and at the same time allowing for innovative billing models, open opportunities in terms of competition, marketing, and profitability that in the past have been restricted to capital equipment and industrial services. Such advantages of industrial services for manufacturers of capital equipment have been discussed in a strand of literature starting in the 1980s (e.g., Anderson et al. 1997; Oliva and Kallenberg 2003; Wise and Baumgartner 1999). Revisiting that literature and transferring its insights to the field of smart consumer products may turn out to be beneficial.

The washing machine as an example shows how adding smartness to a traditional consumer product may increase its impact in the value chain. It is this added value of smart products that goes beyond regular innovations and makes them particularly interesting from the point of view of both managerial decision makers and researchers in the field of innovation management.

As for regular (i.e., non-smart) products, product characteristics, promotion, place (distribution), and price also play a decisive role for the market success of smart products. Techniques that can be used for eliciting preferences for a smart product's characteristics have already been outlined in the preceding section. Promotion and distribution may, but do not necessarily have to be different for smart products. Their smartness (and, particularly, Internet connectivity), however, constitutes a prerequisite for several novel pricing models. The smart washing machine referred to above, for instance, could offer new programs for an additional premium and then immediately initiate the download of new software from the Internet or (temporarily) unlock the 
respective features; in the pay-per-use business model, the machine could provide these programs for a higher price. Another example can be observed in several cities in the Netherlands. Commuters can (voluntarily) equip their cars with transmitters that constantly send GPS data, thus making their cars smarter (to some degree). This way they become eligible to participate in a program that allows them to save money by not using the highways during the rush hour. Data about car movements (location, time, distance, speed, etc.) could likewise be utilized by insurance companies for determining low-risk driving behavior and, accordingly, charging lower premiums (or vice versa). The same may hold for marking and, thus, monitoring high-value items with senders or for equipping houses with humidity sensors for damage prevention both of which enable business models in which insured loss can be reduced and, consequently, insurance premiums can be lowered (corresponding cases are described by Bauer et al. 2013; Strauss et al. 2009).

Since insufficient market analysis and/or inadequate marketing mix measures are the most common reasons for failure of innovations (Cooper 2001) managers regularly seek support to make better decisions in these respects. Corresponding techniques from management science that already have been applied to various (smart or non-smart) products can be roughly distinguished in three groups.

The first group comprises (qualitative or quantitative) forecasting techniques. Among them, scenario analysis has become increasingly common in business planning (Bradfield et al. 2005) and indeed seems to have a more positive effect on decision quality (Meissner and Wulf 2013), the decision-making process as a whole (Chermack 2005), and ultimately corporate performance (Phelps et al. 2001) in general and innovation management in particular (Von der Gracht and Stillings 2013); an overview of scenario techniques is provided by Bishop et al. (2007). In Germany, the "Pictures of the Future" by Siemens (2015) may serve as an illustrative example. Another application can be found in the Leading-Edge Cluster "it's OWL" (short for Intelligent Technical Systems OstWestfalenLippe) in which one of the research projects is dedicated to provide companies with competencies for developing scenarios (cf. IT'S OWL 2015).

The "Bass Model" (which has been voted among the most influential papers published in the 50-year history of the journal Management Science) and its successors form a second group of approaches (for the basic model cf. Bass 1969; an overview of extensions can be found in a collective volume edited by Mahajan et al. 2000). They aim at modeling market behavior from a top-down perspective. Following Rogers' (1962) theory concerning the diffusion of innovations referring to innovators, early adopters, early majority, and laggards, diffusion of an innovation is modeled as a contagious process driven by external influence (e.g., advertising) and internal influence (e.g., word-of-mouth). Apart from the innovators, adoption by the remaining customers is therefore fueled by imitation for which the conditional likelihood of adoption at time $t$ is a function of the number of previous adoptions. The strength of this approach lies in the low number of parameters that are required for the basic hazard model $\frac{f(t)}{1-F(t)}=p+q \cdot F(t)$, where $f(t)$ represents the probability of adoption at time $t$ and $F(t)$ is the cumulative distribution function of adoptions at time $t$. Accordingly, just three parameters are needed, namely for the extent of the external 
influence $p$, for the extent of the internal influence $q$, and for the potential market size $M$. Still, the model (ex post) fits the typical S-shaped curve of product adoption quite well (Bass et al. 1994) and is in particular excellent at backcasting (for an analysis cf. Sultan et al. 1990). When used for forecasting (such as for planning the launch of a satellite television system; cf. Bass et al. 2001) these parameters have to be "guessed by analogy," i.e., parameters $p$ and $q$ have to be determined from similar products (or services) from a database and the market potential $M$ may be estimated based on known market characteristics and perhaps supplemented by intentions data from surveys (Bass 2012). However, the elegant theory underlying the Bass model comes with several shortcomings (for a detailed discussion cf. Chandrasekaran and Tellis 2007). First and foremost, the required parameters can only be estimated with sufficient accurateness if data for similar products and/or markets is available. The approach also widely neglects the impact of various marketing mix variables (although there have been some attempts to account for advertising data and pricing, e.g., by Robinson and Lakhani 1975), micro-level drivers of adoption, supply-side limitations, or spatial aspects of innovation diffusion. Moreover, it provides only limited theoretical insight into why diffusion processes succeed or fail. Nevertheless, numerous papers based on the Bass model have been published and they have been applied to many cases. A recent approach for multi-generation diffusion by Jiang and Jain (2012), based on the generalized model by Norton and Bass (1987), may serve as an example.

Agent-based market simulation approaches constitute the third, and most recent, group of approaches. They follow a bottom-up modeling paradigm and focus on individual stakeholders such as consumers, producers, or points of sale. Each of them is represented by an agent with individual (heterogeneous) characteristics such as, for instance, the purchasing behavior or preferences for product attributes and distribution channels. Furthermore, these agents interact with each other (e.g., by means of word-of-mouth with other agents in the social network) and/or with their environment. The complex system behavior of a market thus emerges from relatively simply local interactions and, by tracking the simulation results (and averaging it over several runs), can be easily captured. The particular strength of an agent-based approach can therefore be found in its ability to provide decision makers with an opportunity to simulate the impact of variants for the marketing mix in advance, i.e., before expensive marketing measures have been applied, and to analyze their effects on innovation diffusion. The challenge in setting up such a market simulation, though, lies in the need to properly model consumer adoption behavior (e.g., their purchasing behavior), social influence (e.g., the interaction topology, word-of-mouth, or effects of normative influence), influence of consumer heterogeneity (e.g., with respect to the propensity to adopt, reservation prices, communication behavior, or socio-demographic issues), and the effects of marketing mix measures (e.g., which consumers are affected by which measure and to what extent). Moreover, the underlying model has to be implemented in a software tool (for an overview cf. Stummer and Kiesling 2012), the required data for parameterizing the market simulation has to be collected (e.g., by means of conjoint analysis for retrieving proper preference data as discussed in Sect. 3 and suggested by Garcia et al. 2007), and simulation results have to be validated in order to ensure that they also reflect and explain processes from real markets (an example can be found in Stummer et al. 2015; for a more general discussion cf. Fagiolo et al. 2007). An 
excellent overview on agent-based modeling for innovation diffusion and a discussion of its pros and cons in comparison with the Bass model is provided by Kiesling et al. (2012); for a further review see Wakolbinger et al. (2013) and for research perspectives in this field also see Peres et al. (2010). An illustrative application example of an agentbased simulation of market diffusion of a novel biomass fuel is described by Günther et al. (2011). Further recent applications are provided by Sonderegger-Wakolbinger and Stummer (2015) and Zsifkovits and Günther (2015).

For the prospective market introduction of smart products, approaches from all three groups of management science approaches may be of value for innovation managers. Forecasting and, particularly, scenario planning can support their decision process in cases in which smart products will supposedly create new or considerably extended markets. Scenarios then can be used to describe these markets and their characteristics and, thus, to gain a better understanding of future consumer needs and expectations (e.g., the possibility to interact with the environment and with others by means of, for instance, Google glass or similar systems), existing as well as new players in the market (e.g., new competitors from other industries, government executing new regulations, etc.), further distribution channels, additional business models, and/or altered market behavior in general. These descriptions of potential "futures" will be valuable for deriving parameters when modeling prospective markets for smart products (e.g., the smart car or the smart home that has been mentioned in Sect. 2). As long as data from the market introduction of similar products are available, Bass model-type approaches may be of help as well. This particularly holds for smart products that are meant as substitutes for non- or less smart products, e.g., a blinder that is not (strongly) interconnected with other smart appliances in the household and therefore can be described as a helpful gimmick. For radical (disruptive) innovations that possess the potential to be a "game changer" for an existing market or for the creation of a new market (more so, if they come along with a service innovation as part of a novel business model such as "renting" a smart service instead of buying a non-smart product), however, data for parameterizing a top-down Bass model will not be available with the required accurateness. This probably will be the case for many of the smart products that have been envisioned in Sect. 2. In these instances, agent-based approaches may come into play. In combination with novel means for eliciting customers' preferences and willingness to pay for additional (novel) attributes or functionalities (as has been discussed in Sect. 3), a market simulation therefore constitutes a promising approach for considerably better representing future complex (macro-level) market behavior by modeling the (micro-level) behavior of involved stakeholders. Such a simulation can also be used for analyzing and discussing alternative marketing mix strategies for diverse scenarios that have been created in advance.

Modeling markets for smart products comes with additional challenges that makes research in this field even more interesting. With respect to the stakeholders to be modeled, for instance, it may become necessary to take into account intermediaries (in addition to producers and customers). In the case of smart homes, these may be architects, property developers, and/or craftsmen (e.g., electricians). Obviously, their experiences, preferences, and/or incentives can play a crucial role when it comes to deciding whether or not to purchase a smart product and, if so, which features will be implemented. For the same reasons, and even more so if large investments have 
to be made (e.g., a construction project for a residential care home for the elderly), approaches for supporting (fair) group decisions and for the resolution of potentially arising conflicts will be required. Next, multiple criteria need to be considered when planning the market introduction of a smart product. The list of criteria may include costs for development and market introduction (which affects awareness and availability of potential customers), prospective profits (which relies on the product's price), timing, and/or strategic considerations (concerning cannibalism of other products, image of the firm, etc.). Accordingly, a multi-criteria decision support system may be required (e.g., an interactive system such as the one proposed by Stummer and Heidenberger 2003). To this end, simulation-optimization approaches should be developed that, for each scenario under consideration, allow for determining Pareto-efficient marketing mix variants (for an example in a different context cf. Kiesling et al. 2014) and subsequently support decision makers in identifying their individual "best" solutions. Since for real-world problem instances such approaches are expensive computationwise, meta-heuristic solution procedures have to be identified and fine-tuned (for an overview of potential algorithms cf. Ehrgott and Gandibleux 2004 or Talbi et al. 2012). From a technical/methodical point of view the latter could turn out to be an intriguing task. Finally, from a modeler's perspective it will be essential to integrate all 'the right issues' in 'the right way' which will require interdisciplinary and transdisciplinary collaboration with (innovation) managers responsible for the market introduction of the smart products in order to cover the market perspective, experts from the underlying technical fields in order to learn about the specifics of the alternative systems and to understand their potential pros and cons, sociologists and psychologists as far as mental or other barriers have to be overcome in the adoption process, in some cases lawyers to cover any legal concerns (since smart products often raise data protection issues and/or liability issues; for the latter, smart cars serve as a prominent example, but the same issues may apply for other smart devices as well), and representatives for all the groups of prospective users of these products. Furthermore, modeling a market in which a smart product should be introduced may require the consideration of policy makers and their specific interests (e.g., concerning the limitation of energy and/or resource consumption which may be actuated by subsidies and/or enforced by regulations). Also, consumers' perceptions of various smartness features such as autonomy, human-like interaction, ability to cooperate, reactivity, adaptability, or multi-functionality may play a role- the more so, since they can raise concerns regarding trustworthiness and control which affects technology acceptance and thus adoption and diffusion of smart products. Accordingly, it needs to be questioned whether smart(er) products are always better. In order to address this issue, consumers' attitudes, consumption values, and behavioral usage intentions toward smart products need to be investigated more closely. Moreover, it will also be worthwhile to take a closer look at normative social influence in the adoption process that may counteract or strengthen the above concerns. Finally, network effects add an interesting perspective, since some gains of smart products depend on the availability of other products that they can interact with. For instance, the ability of a "smart car" to automatically avoid being stuck in a traffic jam will increase with the number of other smart cars it can communicate and coordinate with. It is of further note that such network effects not only apply for products from the same product category (e.g., 
cars), but also may play a role for diverse products as long as they are embedded in a common framework (e.g., they have been developed by the same company or are subject to the same (communication) standards). Devices from Apple vs. devices with an Android operating system may serve as an example. As long as consumers remain within the Apple or the Android "world", respectively, the various devices and services are seamlessly integrated which makes it straightforward to add another smart product and, thus, to benefit from the aforementioned network effects.

In summing up, various techniques from management science have already been applied in the past for providing decision support to (innovation) managers in the context of new product (services) market introduction. However, the analysis of innovation diffusion mechanisms for smart products differs from that of traditional products in several respects. It therefore will be necessary to adapt models and/or to combine approaches (e.g., scenario planning, agent-based simulation, multi-objective simulation-optimization based on meta-heuristic solution procedures, and interactive decision support) in order to shed more light on the as yet vague assumptions about the market diffusion process of smart products. As a result, either manufacturers or intermediaries will gain deeper insight into market dynamics and thus will be supported in making better-informed decisions regarding market entry strategies and/or diffusion management.

\section{Supply chain design}

In the preceding section, the focus was on markets and decisions such as rollout of and marketing strategies for smart products. However, a number of further questions have to be answered referring to the supply side of smart products as well. Some of the challenges to the management of supply chains arise as a result of the fact that firms from previously more or less unrelated industries have to cooperate in order to develop, construct, and distribute smart products. Supply chain management (SCM) primarily deals with issues of configuration of and coordination within the supply chain (SC) (Swaminathan and Tayur 2003). SC configuration relates to the design of the SC infrastructure while the focus of SC coordination is on the short-term management of SC operations. Decisions on the flow of materials, information, and cash are important examples of coordination topics. Designing the supply chain, on the other hand, encompasses decisions on the number and selection of suppliers, on making or buying certain parts, on the contracts underlying the cooperation within the SC, the production infrastructure, the distribution channel, and the information support system. It is predominantly this latter sphere of longer-term SC management decisions which is affected by the specifics of supplying smart products. Some of the resulting problems are the transition from a lean to a more agile design of the supply chain once a new smart product is introduced, the necessity to rely on different SC strategies in parallel for traditional and smart products, and the design of SC contracts for companies from different industries cooperating in $R \& D$ as well as the manufacturing of smart products. In the following, these configuration problems are discussed from a management science point of view. 
Whether or not a specific SC design or SC strategy is suitable for a firm will in general depend on the characteristics of its product. Since Fisher's (1997) publication on the distinction between functional and innovative products and the appropriate design of the corresponding supply chain a considerable body of research has evolved extending this typology and analyzing its analytical and empirical validity (see Lo and Power 2010, for a recent overview and an empirical study; Wang et al. 2004, present an AHP based approach to the product-driven SC selection). When revisiting the examples of smart products given in Sects. 1 and 2 one easily observes that the bulk of smart products listed there are based on familiar, well-established products providing a solution to certain needs of the customer. The manufacturers turn them into smart products by adding new components supporting intelligencegenerating technologies like sensors and actors or components allowing for system integration, communication, data processing, etc. (Meyer et al. 2009). The original products are often well established in the market place and characterized by having a stable demand profile and market share, a longer life cycle, and a relatively low product variety, i.e., they are functional products under Fisher's (1997) typology. Hence, following the theory building on this classification, we should expect that the manufacturers of those familiar products apply a lean SC design, focusing on cost efficiency, continuous process improvement, elimination of non-value activities etc. (Huang et al. 2002).

Adding intelligence-generating technology components to traditional products in order to turn them into smart products is in general bound to change that setting. Depending on the degree of innovation that comes along with the conversion from standard to smart product, smart products will fall into the categories of innovative or hybrid product. These are characterized by, e.g., new markets, uncertain demand, and an unstable product design driven by changing customer requirements (Huang et al. 2002). The supply process for smart products will be less stable and more evolving compared to established products (Lee 2002). Following the literature on the association of product characteristics and SC strategy this implies that the design of the supply chain has to be adjusted accordingly, from lean to more agile, at least for smart products.

As a consequence, SC management will have to cope with the co-existence of different SC strategies for the traditional and the smart varieties of a product, e.g., the traditional washing machine and its smart sister. Supply chains of what seem on first sight to be closely related products of the same firm need to differ considerably with respect to design and management. Even the complete transition from one kind of SC design to another may occur if the traditional product were to be squeezed out of the market entirely in the longer run.

Such transitions in SC strategy following changes in product characteristics would not be a novel occurrence. Transformations of the textile supply chain and the coexistence of different SC strategies, e.g., in the apparel industry, show a prominent example for similar processes. In recent years, these phenomena have sparked a considerable amount of research that has applied management science and game theory (newsboy problem, Nash equilibria, simulation) to analyze the building blocks of the appropriate SC design (e.g., Cachon and Swinney 2011; Hilletofth and Hilmola 2008). It is to be expected that research on the necessary re-shaping of smart product supply 
chains could benefit from this body of SCM literature and accordingly refine and adapt its models and methods.

Intelligence-generating technologies will often not belong to the original spectrum of technological capabilities of the firm. Rather, engineering knowledge in both areas may be quite unrelated. Hence the question arises whether or not decision makers should invest in building up required skills in the new technological field within their own firm, or maybe even its own production capacities. If so, should this be a purely in-house solution or is the integration of some start-up company specializing in this field the more efficient way? Or should the decision maker rely on a supplier of intelligence-generating technology components?

Of course, the due evaluation of costs and benefits of these alternatives will play its role in answering these questions (make or buy analysis). But if a smart product manufacturer intends to cooperate with a supplier this cooperation will in general encompass joint R\&D efforts, because the two companies are from different areas of expertise. Hence the R\&D cooperation within the supply chain and the design of the corresponding contracts touching on, among other aspects, risk sharing, specific investments, and appropriate mutual levels of research effort will become issues. Some analytical, game-theoretical research has been published on joint R\&D in the supply chain that might serve as a starting point for an analysis of these questions in the context of smart products. For example, Iyer et al. (2005) analyze a model in which the manufacturer delegates part of the product specification and production activities to a supplier but may assist the supplier with his/her own engineering resources. Their results depend significantly on whether the (engineering) resources of the supplier and the manufacturer are substitutes or complements, which echoes the situation just discussed for the supply chain for smart products. Kim and Netessine (2013) evaluate the suitability of different types of SC procurement contracts for situations in which the supplier develops and manufactures a component of an innovative product. Demand variability turns out to be a decisive driver of the contract design. A related problem, namely finding the right partners for developing complex system innovations, is addressed by Venghaus and Stummer (2015). For a recent overview of the limited SCM literature on R\&D collaboration within the supply chain and for the subsequent game-theoretical analysis of a specific type of corresponding contractual design confer the work by Ulrich (2014). Apparently, there is research on R\&D cooperation within the SC, but the task to further develop it in order to also cover the field of smart products remains unsolved to date.

In yet another stream of SCM literature the confidentiality with which the supplier treats the information he/she gains from the manufacturer and the repercussions of his/her behavior on SC profits and SC efficiency have been analyzed (Kong et al. 2013). While the literature focuses on market and price information, R\&D cooperation within the supply chain is always associated with a potential spill-over of technological information. In the case of smart products, the dissemination of some of the manufacturer's proprietary information might even be desirable. A smart product in general is only a single item out of a number of elements in a larger smart system that can only yield its entire usefulness to the customer as a whole. Hence SC efficiency might increase if the manufacturers of other components of the smart products as a result of a breach of confidentiality have adopted technical solutions of the firm and 
thus have increased the system's value for the customer. For example, the smart home might be of greater use to its inhabitants if heating, home appliances, etc., and the also smart car relied on standardized interfaces between the various intelligence-generating technologies.

Besides these direct consequences, the integration of intelligence-generating technologies into a firm's product may also have a secondary impact on the SC design. New technologies will contribute to the costs of parts as well as materials and hence create cost pressure on other sections of the supply chain including the firm itself. Corresponding to the importance new technologies have for the purchasing decision of the customer, bargaining power, prices, and profitability of suppliers and manufacturer may alter, resulting in changing design or operation of that section of the overall supply chain which bears responsibility for traditional components (Lovejoy 2010).

The downstream part of the supply chain for smart products may have to adapt to new challenges as well. Closely related traditional and smart products may require different distribution channels. While, for example, traditional household appliances are often sold via stationary or online retailers, smart products may need to be explained to the customer or even integrated into the corresponding smart products by a specialistas it is the case for insurance and other financial products.

\section{Industry development}

The development of smart products is closely linked with the evolution of industrial structures. Diffusion on a large scale requires industrial structures which provide firms with incentives for sufficient investments in production capacities as well as product and process innovation activities such that the relationship between costs and quality of the products generates sufficient demand. Several aspects of smart products seem of paramount importance in this respect and some of them give rise to interesting new research challenges. Firstly, at this point it is still quite unclear which kind of smart products will be able to gain a solid long run position in the market. As has been shown in a large body of literature on industry life-cycles (e.g., Klepper 1996; Utterback and Abernathy 1975) the substantial uncertainty in a young industry typically inhibits investments in process innovation and production capacities until a 'dominant design' has emerged. In the case of smart products this typical uncertainty seems to be reinforced by the fact that firms from different industries compete for a leading position in the emerging markets (e.g., electronics producers vs. established household appliance producers). As has been argued by Mazzucato (2013), relying on a large set of case studies, public investment might play a crucial role in pushing innovations in such early stages. Secondly, in the case of smart products this general phenomenon of initial (private) underinvestment in the early stages of market development seems to be magnified by considerable complementarities between investments of suppliers of different parts of the systems and by standardization issues. If we consider as an example of smart products the development of smart homes in which lighting, heating, ventilation, shades, household appliances and so forth are all to be coordinated and to be controlled according to individual profiles of different household members, it becomes clear that such a system can only work efficiently if there are well-established 
interfaces and communication standards that allow coordination between the different parts. Equipping products with such interfaces, thereby opening up the possibility for integration into a smart home, is costly for producers (development, adjustment of production processes) and in many cases goes beyond the core competences that have been accumulated in the past. Cooperations in the product development domain are often essential for developing the necessary common standards and interfaces. In this regard, a growing number of workgroups such as IEEE Smart Grid or the Open Group IoT provide companies with platforms for the joint development of industry standards and interfaces. However, these costly activities will only generate appropriate long run returns if the other contributors to the smart product also show similar effort and thereby a sufficiently large part of consumers is convinced by the attractiveness of the offered system and the expectation of the persistence of this design in the market. A good illustration of the problems of standardization is the observation that up to now no common standards for charging stations of electric cars have been developed in spite of substantial political efforts to foster the diffusion of these products (see, e.g., Amsterdam Round Table Foundation 2014).

Closely related to the issue of the establishment of standards is the question which platforms will emerge as the main instrument for users to control their (system of) smart products. In particular for systems of consumer products, like smart homes, established platforms like smart phone operating systems seem to be the prime candidates, which raises a number of issues with respect to path dependencies and the potential transfer of market power from the domain of platform providers into the value chain of smart products. Alternatively, one could envision the attempt of (alliances of) producers of smart products to establish their own platforms or the entry of suppliers of specialized platforms enabling users to communicate with a particular type of smart products.

Whereas the basic logic underlying the threat of underinvestment in cases of investment complementarities is well understood (see, e.g., Cooper 1999) and the implications of complementarities for investment incentives have been analyzed extensively using game theoretic models (e.g., Dawid and MacLeod 2008), the question of how to overcome such obstacles for industrial development in the framework of different concrete market environments is quite challenging. Specific characteristics of the product under consideration, the associated production processes, the structure of the supply chains as well as the industry structure should be considered and it seems to be essential to allow for a dynamic perspective in the analysis. Similar statements apply to the issue of platform competition which so far in the literature has been primarily analyzed in rather abstract and static settings (see, e.g., Armstrong 2006, or the survey by Evans et al. 2005). Industry simulation models have been proven to be very useful for the examination of the effects of different kinds of firms' strategies and public interventions on industry evolution. In a series of papers presenting 'history-friendlymodels' (e.g., Malerba et al. 1999; Malerba and Orsenigo 2002) particular industries, like the biotech industry or the PC industry, have been considered and agent-based simulation models have been developed which capture key features of actual firm behavior on the micro level and at the same time are able to reproduce empirically observable industry evolution patterns as simulation output. In Malerba et al. (2001) it has been shown how such an approach can then be used to gain insights into the (counterfactual) effects of different industrial policy measures. Colombo et al. (2012) employ an agent- 
based simulation model to explore the implications of the industrial environment, like the availability of venture capital financing, for the evolution of an industry. Furthermore, as has been demonstrated for example in Dawid and Reimann (2004, 2011) agent-based simulation models can also be employed for normative analyses of firm behavior. In these papers the performance of different firm strategies are compared in a dynamic industry model, in which the different aspects of industry evolution, in particular the ranges of products offered on the market, the life cycles of the different products as well as the dynamics of production costs are endogenously driven by the interplay of the strategies of the competitors on the market. Firm strategies in these models are represented by relatively simple parameterized families of decision rules inspired by well-documented heuristics of real world firms (cf. Dawid and Harting 2012). Evaluating the (expected) performance of strategies based on batches of simulation runs carried out under various assumptions about the strategies of the other firms allows a sound understanding of the effectiveness of different types of strategies in different industry environments. Conceptually, such insights are closely related to 'best response functions' in game theory. Such a type of analysis provides normative guidance for the design of firm strategies, but, under the assumptions that firms adjust their strategies over time toward those with the highest expected performance, it can also be used to explore (distributions of) industry evolution scenarios under different assumptions about market design and public policies. The strong dynamic complementarity and standardization issues present in the development of smart products have not so far been examined using such tools, but it seems that industry simulations of that kind could be very helpful in exploring which combination of firm strategies, firm cooperation schemes and industrial policies might be most suitable for facilitating the sustainable growth of related industries.

Public policy can be seen as a crucial factor for diminishing the under-investment problems sketched above, thereby facilitating the development and diffusion of smart products. Among those policy measures, tax incentives and subsidies for innovative investments in smart products seem particularly relevant. At this point the insights concerning the impact of different fiscal measures in this area are, however, rather limited (e.g., Hall and van Reenen 2000). Hence, a rigorous quantitative analysis of the efficiency of different potential fiscal incentive schemes would seem to be an important step for gaining a better understanding of the factors inhibiting or, conversely, facilitating smart product diffusion. In this question one has to differentiate between subsidies based on taxable income, tax liability, or the tax rate, respectively. Based on established methods from tax-planning analysis, different potential measures (and such that are to some extent already applied in various countries) could be analyzed with respect to their effectiveness. Arguably, the different measures considered here will not only have positive implications for investment by reducing the tax-burden on firms, but might also lead to distortions of the structure of investment choices relevant for the development of smart products. Arguments like this give rise to a discussion of the proper design of public R\&D promotion schemes that minimize such distortions. The consideration of a suitable reference system for taxation, like the taxation of true economic profit, has an important role in such a discussion. The large uncertainty about the future development of markets for smart products makes such a discussion particularly challenging. Real option theory provides tools for dealing 
Table 1 Exemplary/promising techniques from management science to be applied

\begin{tabular}{lllll}
\hline & $\begin{array}{l}\text { Consumer } \\
\text { preference } \\
\text { elicitation }\end{array}$ & $\begin{array}{l}\text { Market } \\
\text { analysis }\end{array}$ & $\begin{array}{l}\text { Supply } \\
\text { chain design }\end{array}$ & $\begin{array}{l}\text { Industry } \\
\text { development }\end{array}$ \\
\hline Analytic hierarchy process & $\checkmark$ & $\checkmark$ & $\checkmark$ & $\checkmark$ \\
Conjoint analysis & $\checkmark$ & $\checkmark$ & \\
Diffusion modeling & $\checkmark$ & $\checkmark$ & $\checkmark$ \\
Game theory & & $\checkmark$ & $\checkmark$ \\
Interactive decision support & & $\checkmark$ & \\
Multi-objective simulation optimization & & $\checkmark$ & \\
Principal agent theory & & & \\
Real options & & $\checkmark$ & \\
Scenario analysis & & $\checkmark$ & \\
Simulation (incl. agent-based simulations) & & & \\
Survey-based preference analysis & $\checkmark$ & & \\
\hline
\end{tabular}

with investments under uncertainty (e.g., Van Bekkum et al. 2009; Schwartz 2004; Fredberg 2007; Huisman and Kort 2015). Although some criticism of the assumptions underlying the real options approach are certainly justified, at this point it seems to be the most promising method available in order to analyze the impact of fiscal policy measures on investment decisions under uncertainty.

The comparison of different legal firm structures, and, related to that, of different ways of financing investment in smart products, is another challenging topic for future research. The focus in such research should be on the relevant norms induced by civil law and corporate law, including patent law (cf. Czarnitzki and Toole 2011). This also comprises the examination of potential cooperation between firms (e.g., joint ventures) in order to generate synergies, coordinate the management, and hedge the risk. Such considerations should be seen as complementary to the analysis of fiscal incentives, since the choice of the firm structure under which investments are carried out might be influenced by tax considerations and the most crucial factor in determining the tax burden is the chosen legal and organizational structure of the firm (cf. Shevlin 1987).

\section{Conclusions}

Recent explorative studies as well as interviews with managers from various industries conducted by iTIME ${ }^{1}$ leave little room for doubt that smart products may become "the next big thing". The overall impression is that technical obstacles have been widely

\footnotetext{
1 The Institute for Technological Innovation, Market Development, and Entrepreneurship (iTIME) is established at the Department of Business Administration and Economics at Bielefeld University. It serves as a platform for an interdisciplinary cooperation between researchers from within this department as well as with researchers from the Cluster of Excellence Cognitive Interaction Technology (CITEC). The research focus of iTIME is set on economic implications of smart products and smart systems, respectively.
} 
overcome. However, several economic challenges still exist. On the intra-firm level, these are mostly located in the intersection between innovation management and marketing as well as supply chain management. On a more strategic level, firms are primarily interested in potential implications of the era of smart products for their markets with respect to changes to market structure or the emergence of new markets and/or in positioning the firm in the new markets (for an overview over strategic implications cf. Porter and Heppelmann 2014). For several of these concerns, management science has either proved to be of value since it already has been successfully applied in similar contexts or its techniques are, in principle, capable of properly addressing these needs. For a non-exhaustive list of such references to management science approaches as described in this paper see Table 1.

It is quite apparent that the widespread introduction of smart products will raise various managerial challenges for decision makers from several industries. This paper has hinted at some techniques that can be applied to analyze, address, and, ideally, solve these problems, as well as to open research issues. The main contribution of this paper therefore lies in pointing to rewarding research opportunities for management science in the era of smart products.

Acknowledgements The authors thank two reviewers as well as Dietmar Bauer for their valuable comments on an earlier version of this paper. This research was supported by the Cluster of Excellence Cognitive Interaction Technology 'CITEC' (EXC 277) at Bielefeld University, which is funded by the German Research Foundation (DFG).

Open Access This article is distributed under the terms of the Creative Commons Attribution 4.0 International License (http://creativecommons.org/licenses/by/4.0/), which permits unrestricted use, distribution, and reproduction in any medium, provided you give appropriate credit to the original author(s) and the source, provide a link to the Creative Commons license, and indicate if changes were made.

\section{References}

Agarwal J, DeSarbo WS, Malhotra NK, Rao VR (2015) An interdisciplinary review of research in conjoint analysis: recent developments and directions for future research. Custom Needs Solut 2(1):19-40

Ahram T, Karwowski W, Soares MM (2011) Smarter products user-centered systems engineering. In: Karwowski W, Soares MM, Stanton NA (eds) Human factors and ergonomics in consumer product design. Taylor \& Francis, Boca Raton, pp 83-94

Allmendinger G, Lombreglia R (2005) Four strategies for the age of smart services. Harv Bus Rev 83(10):131-145

Amsterdam Round Table Foundation (2014) Electric vehicles in Europe: gearing up for a new phase? McKinsey, Amsterdam

Anderson EW, Fornell C, Rust RT (1997) Customer satisfaction, productivity, and profitability: differences between goods and services. Mark Sci 16(2):129-145

Ayağ Z (2016) An integrated approach to concept evaluation in a new product development. J Intell Manuf (forthcoming)

Armstrong M (2006) Competition in two-sided markets. RAND J Econ 37(3):668-691

Bass FM (1969) A new product growth for model consumer durables. Manag Sci 15(5):215-227

Bass FM (2012) Comments on a new product growth for model consumer durables. Manag Sci 50(12 Supplement): $1833-1840$

Bass FM, Gordon K, Ferguson TL, Githens ML (2001) DIRECTV: forecasting diffusion of a new technology prior to product launch. Interfaces 31(3 Suppl):82-93

Bass FM, Krishnan TV, Jain DC (1994) Why the Bass model fits without decision variables. Mark Sci 13(3):203-233 
Bauer C, Strauss C, Stummer C, Trieb A (2013) Context-aware services in cooperative value chains: a key player-centred approach. Scalable Comput Pract Exp Sci Int J Parallel Distrib Comput 14(3):139-153

Bishop P, Hines A, Collins T (2007) The current state of scenario development: an overview of techniques. Foresight $9(1): 5-25$

Bogers M, Horst W (2014) Collaborative prototyping: cross-fertilization of knowledge in prototype-driven problem solving. J Prod Innov Manag 31(4):744-764

Bohn J, Coroamă V, Langheinrich M, Mattern F, Rohs M (2004) Living in a world of smart everyday objects: social, economic, and ethical implications. J Hum Ecol Risk Assess 10(5):763-786

Bradfield R, Wright G, Burt G, Cairns G, van der Heijden K (2005) The origins and evolution of scenario techniques in long range business planning. Futures 37(8):795-812

Cachon GP, Swinney R (2011) The value of fast fashion: quick response, enhanced design, and strategic consumer behavior. Manag Sci 57(4):778-795

Chandrasekaran D, Tellis GJ (2007) A critical review of marketing research on diffusion of new products. In: Malhorta NK (ed) Review of marketing research. Sharpe, Armonk, pp 39-80

Chang YP, Dong XB, Sun W (2014) Influence of characteristics of the Internet of Things on consumer purchase intention. Soc Behav Personal 42(2):321-330

Chermack TJ (2005) Studying scenario planning: theory, research suggestions, and hypotheses. Technol Forecast Soc Change 72(1):59-73

Clancy KJ, Krieg PC, Wolf MM (2006) Market new products successfully. Lexington Books, Lexington

Clancy KJ, Shulman RS, Wolf MM (1994) Simulated test marketing: technology for successful new products. Lexington Books, Lexington

Colombo L, Dawid H, Kabus K (2012) When do thick venture capital markets foster innovation? An evolutionary analysis. J Evol Econ 22(1):79-108

Cooper RG (2001) Winning at new products: accelerating the process from idea to launch, 3rd edn. Perseus, Cambridge

Cooper RW (1999) Coordination games: complementarities and macroeconomics. Cambridge University Press, Cambridge

Czarnitzki D, Toole AA (2011) Patent protection, market uncertainty, and R\&D investment. Rev Econ Stat 93(1):147-159

Dawid H, Harting P (2012) Capturing firm behavior in agent-based models of industry evolution and macroeconomic dynamics. In: Bünsdorf G (ed) Applied evolutionary economics, behavior and organizations. Edward Elgar, Cheltenham, pp 103-130

Dawid H, MacLeod WB (2008) Hold-up and the evolution of investment and bargaining norms. Games Econ Behav 62(1):26-52

Dawid H, Reimann M (2004) Evaluating market attractiveness: individual incentives vs. industry profitability. Comput Econ 24(4):321-355

Dawid H, Reimann M (2011) Diversification: a road to inefficiency in product innovations? J Evol Econ 21(2):191-229

Decker R, Trusov M (2010) Estimating aggregate consumer preferences from online product reviews. Int J Res Mark 27(4):293-307

Ehrgott M, Gandibleux X (2004) Approximative solution methods for multiobjective combinatorial optimization. Top 12(1):82-85

Evans DS, Hagiu A, Schmalensee R (2005) A survey of the economic role of software platforms in computerbased industries. CESifo Econ Stud 51(2-3):189-224

Fagiolo G, Moneta A, Windrum P (2007) A critical guide to empirical validation of agent-based models in economics: methodologies, procedures, and open problems. Comput Econ 30(3):195-226

Fisher ML (1997) What is the right supply chain for your product? Harv Bus Rev 75(2):105-116

Fredberg T (2007) Real options for innovation management. Int J Technol Manag 39(1-2):72-85

Garcia R, Rummel P, Hauser J (2007) Validating agent-based marketing models through conjoint analysis. J Bus Res 60(8):848-857

Gaubinger K, Rabl M, Swan S, Werani T (2015) Innovation and product management: a holistic and practical approach to uncertainty reduction. Springer, Heidelberg

Godes D, Silva JC (2012) Sequential and temporal dynamics of online opinion. Mark Sci 31(2):448-473

Günther M, Stummer C, Wakolbinger LM, Wildpaner M (2011) An agent-based simulation approach for the new product diffusion of a novel biomass fuel. J Oper Res Soc 62(1):12-20

Hall B, van Reenen J (2000) How effective are fiscal incentives for R\&D? A review of the evidence. Res Policy 29(4-5):449-469 
Handfield R, Walton SV, Sroufe R, Melnyk SA (2002) Applying environmental criteria to supplier assessment: a study in the application of the Analytical Hierarchy Process. Eur J Oper Res 141(1):70-87

Hermann T, Hunt A, Neuhoff JG (eds) (2011) The sonification handbook. Logos, Berlin

Hilletofth P, Hilmola O-P (2008) Supply chain management in fashion and textile industry. Int J Serv Sci 1(2): 127-147

Huang SH, Shi M, Uppal J (2002) A product driven approach to manufacturing supply chain selection. Supply Chain Manag Int J 7(4):189-199

Huang L, Zhang J, Liu H, Liang L (2012) The effect of online and offline word-of-mouth on new product diffusion. J Strateg Mark 22(2):177-189

Huisman KJM, Kort PF (2015) Strategic capacity investment under uncertainty. RAND J Econ 46(2):376408

Ishii H, Ullmer B (1997) Tangible bits: towards seamless interfaces between people, bits and atoms. In: Proceedings of ACM CHI '97 human factors in computing systems conference, pp 234-241

IT'S OWL (2015) Always a step ahead: sustainability initiative forecasting. http://www.its-owl.com/ projects/sustainability-initiatives/details/forecasting/. Accessed 30 Nov 2015

Iyer AV, Schwarz LB, Zenios SA (2005) A principal-agent model for product specification and production. Manag Sci 51(1):106-119

Jiang Z, Jain DC (2012) A generalized Norton-Bass model for multigeneration diffusion. Manag Sci 58(10):1887-1897

Kalluri V, Kodali R (2014) Analysis of new product development research: 1998-2009. Benchmark Int J 21(4):527-618

Kaltenbacher J, Decker R (2014) New product sales forecasting: an approach for the insurance business. World J Manag 5(1):36-53

Kiesling E, Ekelhart A, Grill B, Strauss C, Stummer C (2014) Evolving secure information systems through attack simulation. In: Proceedings of the Hawaii international conference on system sciences (HICSS47). IEEE Computer Society, pp 4868-4877

Kiesling E, Günther M, Stummer C, Wakolbinger LM (2012) Agent-based simulation of innovation diffusion: a review. Cent Eur J Oper Res 20(2):183-230

Kim N, Im S, Slater SF (2013) Impact of knowledge type and strategic orientation on new product creativity and advantage in high-technology firms. J Prod Innov Manag 26(1):136-153

Kim SH, Netessine S (2013) Collaborative cost reduction and component procurement under information asymmetry. Manag Sci 59(1):189-206

Klepper S (1996) Entry, exit, growth, and innovation over the product life cycle. Am Econ Rev 86(3):562583

Kong G, Rajagopalan S, Zhang H (2013) Revenue sharing and information leakage in a supply chain. Manag Sci 59(3):556-572

Körling M (2012) Smart products: why adding a digital side to a toothbrush could make a lot of sense. Ericsson Bus Rev 18(2):26-31

Krishnan V, Gupta S (2001) Appropriateness and impact of platform-based product development. Manag Sci 47(1):52-68

Lee HL (2002) Aligning supply chain strategies with product uncertainties. Calif Manag Rev 44(3):105-119

Lee W-J (2014) Can smart product make customers satisfied? Adv Sci Technol Lett 47:395-398

Lee TY, Bradlow ET (2011) Automated marketing research using online customer reviews. J Mark Res 48(5):881-894

Lo SM, Power D (2010) An empirical investigation of the relationship between product nature and supply chain strategy. Supply Chain Manag Int J 2010(15):139-153

Lovejoy WS (2010) Bargaining chains. Manag Sci 56(12):2282-2301

Luchs MG, Swan KS, Creusen MEH (2016) A review of marketing research on product design with directions for future research. J Prod Innov Manag (forthcoming)

Ma X, Pogrebna G, Ng I (2014) Smart home, smart things and smart me in the smart city: the hub-of-allthings resource integration and enabling tool (HARRIET). In: Proceedings of the IET conference on future intelligent cities, pp 1-6

Maass W, Varshney U (2008) Preface to the focus theme section on Smart products. Electron Mark 18(3):211-215

Mahajan V, Muller E, Wind Y (2000) New-product diffusion models. Kluwer, Boston

Malerba F, Nelson R, Orsenigo L, Winter S (1999) History-friendly models of industry evolution: the computer industry. Ind Corp Change 8(1):3-40 
Malerba F, Nelson R, Orsenigo L, Winter S (2001) Competition and industrial policies in a history friendly model of the evolution of the computer industry. Int J Ind Organ 19(5):635-664

Malerba F, Orsenigo L (2002) Innovation and market structure in the dynamics of the pharmaceutical industry and biotechnology: towards a history-friendly model. Ind Corp Change 11(4):667-703

Mayer P (2010) Economic aspects of smart products. Whitepaper, Institute of Technology Management, University of St. Gallen

Mayer P, Volland D, Thiesse F, Fleisch E (2011) User acceptance of smart products: an empirical investigation. In: Proceedings of the Zurich international conference on Wirtschaftsinformatik, pp 1063-1072

Mazzucato M (2013) The entrepreneurial state: debunking public vs. private sector myths. Anthem Press, London

Meißner M, Decker R, Scholz SW (2010) An adaptive algorithm for pairwise comparison-based preference measurement. J Multi-Criteria Decis Anal 17(5-6):167-177

Meissner P, Wulf T (2013) Cognitive benefits of scenario planning: its impact on biases and decision quality. Technol Forecast Soc Change 80(4):801-814

Meyer GG, Främling K, Holmström J (2009) Intelligent products: a survey. Comput Ind 60(3):137-146

Moe WW, Schweidel DA (2012) Online product opinion: incidence, evaluation and evolution. Mark Sci 31(3):372-386

Mollick E (2014) The dynamics of crowdfunding: an exploratory study. J Bus Ventur 29:1-16

Moore GE (1965) Cramming more components onto integrated circuits. Electronics 38(8):1-6

Norton JA, Bass FM (1987) A diffusion theory model of adoption and substitution for successive generations of high-technology products. Manag Sci 33(9):1068-1086

Oliva R, Kallenberg R (2003) Managing the transition from products to services. Int J Serv Ind Manag 14(2):160-172

Park HJ, Lee HS (2014) Product smartness and use-diffusion of smart products: the mediating roles of consumption values. Asian Soc Sci 10(3):54-61

Peres R, Muller E, Mahajan V (2010) Innovation diffusion and new product growth models: a critical review and research directions. Int J Res Mark 27(2):91-106

Phelps R, Chan C, Kapsalis SC (2001) Does scenario planning affect performance? Two exploratory studies. J Bus Res 51(3):223-232

Porter ME, Heppelmann JE (2014) How smart, connected products are transforming competition. Harv Bus Rev 92(11):64-88

Porter ME, Heppelmann JE (2015) How smart, connected products are transforming companies. Harv Bus Rev 93(10):97-114

Rijsdijk SA, Hultink EJ (2009) How today's consumers perceive tomorrow's smart products. J Prod Innov Manag 26(1):24-42

Rijsdijk SA, Hultink EJ (2013) Developing intelligent products. In: Kahn KB, Kay SE, Slotegraaf RJ, Uban S (eds) The PDMA handbook of new product development. Wiley, Hoboken, pp 297-309

Rijsdijk SA, Hultink EJ, Diamantopoulos A (2007) Product intelligence: its conceptualization, measurement and impact on consumer satisfaction. J Acad Mark Sci 35(3):340-356

Rivera J, van der Meulen R (2014) Garnter says 4.9 billion connected things will be in use in 2015. Gartner. http://www.garnter.com/newsroom/id/2905717. Accessed 16 Nov 2015

Robinson B, Lakhani c (1975) Dynamic price models for new product planning. Manag Sci 21(6):11131122

Rogers EM (1962) Diffusion of innovations. Free Press, New York

Saaty TL (2003) Decision-making with the AHP: why is the principal Eigenvector necessary. Eur J Oper Res 145(1):85-91

Scholz SW, Meißner M, Decker R (2010) Measuring consumer preferences for complex products: a compositional approach based on paired comparisons. J Mark Res 47(4):685-698

Schwartz ES (2004) Patents and R\&D as real options. Econ Notes 33(1):23-54

Shaer O, Hornecker E (2010) Tangible user interfaces: past, present, and future directions. Found Trends Hum Comput Interact 3(1-2):1-137

Shevlin T (1987) Taxes and off-balance-sheet financing: research and development limited partnerships. Account Rev 62(3):480-509

Siemens (2015) Pictures of the future. http://www.siemens.com/innovation/en/publications. Accessed 30 April 2015

Sonderegger-Wakolbinger LM, Stummer C (2015) An agent-based simulation of customer multi-channel choice behavior. Cent Eur J Oper Res 23(2):459-477 
Stummer C, Heidenberger K (2003) Interactive R\&D portfolio analysis with project interdependencies and time profiles of multiple objectives. IEEE Trans Eng Manag 50(2):175-183

Stummer C, Kiesling E (2012) Simulating innovation adoption behavior: lessons learned for modelers and programmers. In: Breitenecker F, Bruzzone AG, Jimenez E, Longo F, Merkuryev Y, Sokolov B (eds) Proceedings of the 24th European modeling and simulation symposium (EMSS-2012). University of Genoa, pp 90-96

Stummer C, Kiesling E, Günther M, Vetschera R (2015) Innovation diffusion of repeat purchase products in a competitive market: an agent-based simulation approach. Eur J Oper Res 245(1):157-167

Strauss C, Stummer C, Bauer C, Trieb A (2009) A networked ubiquitous computing environment for damage prevention: a decision support framework for the insurance sector. In: Proceedings of the international workshop on design, optimization and management of heterogeneous networked systems (DOMHetNet' 09). IEEE Computer Society Digital Library, pp 276-281

Sultan F, Farley JU, Lehmann DR (1990) A meta-analysis of applications of diffusion models. J Mark Res 27(1):70-77

Swaminathan JM, Tayur SR (2003) Models for supply chains in e-business. Manag Sci 49(10):1387-1406

Talbi E-G, Basseur M, Nebro AJ, Alba E (2012) Multi-objective optimization using metaheuristics: nonstandard algorithms. Int Trans Oper Res 19(1-2):283-305

Ulrich CA (2014) Issues in supply chain scheduling and contracting. Springer, Wiesbaden

Urban GL, Hulland JS, Weinberg BD (1993) Premarket forecasting for new consumer durable goods: modeling categorization, elimination, and consideration phenomena. J Mark 57(2):47-63

Utterback JM, Abernathy WJ (1975) A dynamic model of product and process innovation. Omega 3(6):639_ 656

Van Bekkum S, Pennings E, Smit H (2009) A real options perspective on R\&D portfolio diversification. Res Policy 38(7):1150-1158

Venghaus S, Stummer C (2015) Finding partners for complex system innovations through a trans-sectoral matchmaking platform. Technol Anal Strateg Manag 27(3):334-359

Von der Gracht HA, Stillings C (2013) An innovation-focused scenario process: a case from the materials producing industry. Technol Forecast Soc Change 80(4):599-610

Wakolbinger LM, Stummer C, Günther M (2013) Market introduction and diffusion of new products: recent developments in agent-based modeling. Int J Innov Technol Manag 10(5):1-19

Wang G, Huang SH, Dismukes JP (2004) Product-driven supply chain selection using integrated multicriteria decision making methodology. Int J Prod Econ 91(1):1-15

Weiser M (1991) The computer for the 21st century. Sci Am 265(3):94-104

Wise R, Baumgartner P (1999) Go downstream: the new imperative in manufacturing. Harv Bus Rev 77(5):133-141

Wu X, Zhu X, Wu G-Q, Ding W (2014) Data mining with big data. IEEE Trans Knowl Data Eng 26(1):997109

Yang X, Moore P, Chong SK (2009) Intelligent products: from lifecycle data acquisition to enabling productrelated services. Comput Ind 60(3):184-194

Yin S, Kaynak O (2015) Big data for modern industry: challenges and trends. Proc IEEE 103(2):225-228

Zinkhan GM (2003) A look to the future of JAMS: three years out, thirty years out .... J Acad Mark Sci 31(3):225-228

Zsifkovits M, Günther M (2015) Simulating resistances in innovation diffusion over multiple generations: an agent-based approach for fuel-cell vehicles. Cent Eur J Oper Res 23(2):501-522 